Tohoku J. Exp. Med., 2006, 209, 249-255

\title{
Pentoxifylline, a Methyl Xanthine Derivative, Reduces Peritoneal Adhesions and Increases Peritoneal Fibrinolysis in Rats
}

\author{
Omer Ridvan Tarhan, Ibrahim Barut, Recep Sutcu, ${ }^{1}$ Yusuf Akdeniz and \\ ONUR AKTURK ${ }^{1}$ \\ Department of General Surgery, ${ }^{I}$ Department of Biochemistry, Suleyman \\ Demirel University Medical School, Isparta, Turkey
}

\begin{abstract}
Tarhan, O.R., Barut, I., Sutcu, R., Akdeniz, Y. and Akturk, O. Pentoxifylline, a Methyl Xanthine Derivative, Reduces Peritoneal Adhesions and Increases Peritoneal Fibrinolysis in Rats. Tohoku J. Exp. Med., 2006, 209 (3), 249-255 — Peritoneum has an intrinsic fibrinolytic activity that breaks the peritoneal adhesions. Peritoneal injuries with ischemia interfere this fibrinolytic activity and cause adhesions. Pentoxifylline, a methyl xanthine derivative, improves blood flow by decreasing its viscosity and also increases fibrinolytic activity in plasma. We hypothesized that pentoxifylline would increase peritoneal fibrinolysis and ameliorate adhesions. A rat model of peritoneal adhesion (cecal abrasion with gauze, $n=15$ for each group) was used to test this hypothesis and cardinal parameters of peritoneal fibrinolysis were measured in peritoneal samples. No medication was given in control animals, while pentoxifylline was administered intraperitonealy (IP) ( $25 \mathrm{mg} / \mathrm{kg}$, before abdominal closure to whole abdomen) or intravenously (IV) (25 mg/kg, for 9 days after operation) in the experimental groups. At postoperative day 10, peritoneal biopsies were obtained and adhesions were graded qualitatively. Activities and concentrations of tissue plasminogen activator (tPA), plasminogen activator inhibitor type 1 (PAI-1), tPA/PAI-1 complex and hydroxyproline contents were determined. Total adhesion scores were decreased in both treated groups. Mean levels of tPA concentration and TPA activity were increased in the treated groups compared to controls $(p<0.001$ and $p=0.001$, respectively). The tPA/PAI-1 complex levels were similar among the three groups. PAI-1 levels were lower in animals receiving IP pentoxifylline compared to control animals and those treated with IV pentoxifylline ( $p=0.048, p=0.015$, respectively). Peritoneal hydroxyproline levels were similar among the three groups. Our results suggest that pentoxifylline administration either through IV or IP may reduce peritoneal adhesion formation probably by altering peritoneal fibrinolytic activity. —— pentoxifylline; peritoneal adhesion; tPA; PAI-1; peritoneal fibrinolysis

(C) 2006 Tohoku University Medical Press
\end{abstract}

Peritoneal adhesions are defined as fibrous bands of tissue that join together organs that are normally separated. Today, most common cause

of peritoneal adhesions is previous abdominal surgery. Abdominal surgery causes peritoneal adhesions in $93 \%$ of patients (Menzies and Ellis

Received October 17, 2005; revision accepted for publication May 2, 2006.

Correspondence: Omer Ridvan Tarhan, 6 Mart Ataturk Cad., Yasar Aksel Apt. 10/9, 32100, Isparta, Turkey.

e-mail: drtarhan@yahoo.com 
1990). Peritoneal adhesions are an unsolved surgical problem. Abdominal operations cause peritoneal injury and ischemia, contamination of foreign body (talk, cotton and starch powder), desiccation and diathermy in peritoneum.

Peritoneal healing differs from that of skin. The two main differences are epithelization and consequences of fibrin deposition. First, the peritoneal epithelization takes place by the entire surface of the defect simultaneously. Skin epithelization results from migration of epithelial cells from dermal edges. Second, fibrin matrix that was formed after peritoneal injury is broken down via peritoneal fibrinolysis and absorbed under normal circumstances. Fibrin matrix is organized to scar tissue in skin healing.

All injuries to the peritoneum lead to the formation of fibrinous exudate, which is essential for normal tissue repair. Such fibrinous material might either reabsorb completely or become organized into fibrous adhesions. The question is what factor determines the reabsorbsion or organization. Ischemia is the most important determinant (Holtz 1984). If ischemia is absent, epithelization proceeds and fibrin matrix is broken down by fibrinolysis. Normal peritoneum has an inherent fibrinolytic activity. Fibrinolysis is mainly activated by tissue plasminogen activator (tPA) and principal tPA inhibitor is plasminogen activator inhibitor (PAI) type 1. Ischemia reduces fibrinolytic capacity and fibrin matrix changes permanent adhesions (Raftery 1981; Holtz 1984; Menzies 2004).

Pentoxifylline, a methyl xanthine derivative, enhances plasma fibrinolytic activity, reduces plasma fibrinogen levels, inhibits platelet aggregation and increases erythrocyte and leukocyte flexibility (Jarret et al. 1977; Alkharfy et al. 2000; Schroer 1985). Eventually, pentoxifylline improves the flow properties of blood by decreasing its viscosity (Jarret et al. 1977; Schroer 1985). If pentoxifylline increases local (peritoneal) fibrinolytic activity, it possibly reduces peritoneal adhesions. To test this hypothesis, adhesions, fibrinolytic parameters, and hydroxyproline contents of the peritoneal samples were investigated after the pentoxifylline administration in a rat peritoneal adhesion model.

\section{Materials and Methods}

Animals

The Ethics Committee of Suleyman Demirel University Medical School approved the experimental procedures in this study (Suleyman Demirel University Research Fund, Project Number: 864 M 04). Animals were obtained from the breeding unit of Suleyman Demirel University, School of Medicine and "All of the guiding principles in the care and use of laboratory animals" were strictly adhered throughout the entire study.

Forty-five female adult Wistar rats weighing 136 $218 \mathrm{~g}$ were used. Throughout the experiment, animals were given food and water without any limitation. Animals were assigned in three groups randomly $(n=15$ each); control group, intraperitoneal (IP) pentoxifylline group and intravenous (IV) pentoxifylline group.

\section{Anesthesia and experimental design}

The rats were anesthetized with $100 \mathrm{mg} / \mathrm{kg}$ ketamine hydrochloride (Ketalar ${ }^{\circledR}$, Parke - Davis, Morris Plains, NJ, USA), and $25 \mathrm{mg} / \mathrm{kg}$ xylazine hydrochloride (Rompun $^{\circledR}$, Bayer, Mefar Ilac Sanayi, Istanbul, Turkey) intramuscularly. The abdomen was shaved and disinfected with $70 \%$ povidone iodine. All surgical procedures were carried out under sterile conditions. After a $3-\mathrm{cm}$ midline incision had been made, antimesenteric border of cecum was abraded with a dry sterile gauze until punctuate bleeding occurred. In control group no medication was given. Abdominal wall was repaired with 2 - 0 polypropylene (Prolene ${ }^{\circledR}$, Ethicon, Woluwe, Belgium) continuously. In the IP pentoxifylline group pentoxifylline $\left(25 \mathrm{mg} / \mathrm{kg}\right.$; Trental ampul ${ }^{\circledR}, 100 \mathrm{mg} / 5 \mathrm{ml}$, Aventis Pharma, Istanbul, Turkey) was administered to the whole abdominal cavity, with $1: 4$ dilution using sterile water $(5 \mathrm{ml} / \mathrm{kg}$ drug solution). In the IV pentoxifylline group pentoxifylline $(25 \mathrm{mg} / \mathrm{kg})$ was administered on a daily basis via the dorsal tail vein, without dilution, from the day of operation, until 9 days postoperatively with the first dose given preoperatively. Abdominal wall was repaired with 2 - 0 polypropylene continuously. The skin was closed with 2 - 0 polyglactine suture (Vicryl ${ }^{\circledR}$, Ethicon, Woluwe, Belgium) continuously.

At postoperative day 10, a U-shaped incision was made under the anesthesia that was described previously. Adhesions were classified into four groups according to their severity (Evans et al. 1993) (Table 1).

Peritoneal biopsy specimens were taken from the 
TABLE 1. Adhesion grading scale.

\begin{tabular}{cl}
\hline Adhesion grade & \\
\hline Grade 0 & No adhesions. \\
Grade 1 & Filmy and avascular adhesions separated easily by blunt dissection. \\
Grade 2 & Firm and limited vascular adhesions separated by aggressive blunt dissection. \\
Grade 3 & Dense and well-vascularized adhesions separated by sharp dissection. \\
\hline
\end{tabular}

right lower quadrant while the animals were alive. Biopsy specimens were rinsed with normal saline solution and dried with a piece of blotting paper to remove blood. The biopsy specimens were stored at $-80^{\circ} \mathrm{C}$ in airtight tubes until the homogenization.

\section{Homogenization}

For the homogenization of the biopsy specimens, 1 $\mathrm{ml}$ homogenizing solution $(0.1 \%$ Tritron X 100, $2.5 \mathrm{mM}$ sodium dihydrogen phosphate, $0.075 \mathrm{M}$ sodium chloride) was added for every $40 \mathrm{mg}$ tissue. After the biopsy specimens were homogenized in an Ultra Thurrax IKA T - 25 (Janke \& Kunken, Staufen, Germany) homogenizer for 3 min, the homogenates were sonicated (Bandelin Electronic, Berlin, Germany) for $30 \mathrm{sec}$. The homogenates were centrifuged at $4,000 \mathrm{~g}$ for $20 \mathrm{~min}$ and supernatants were stored at $-80^{\circ} \mathrm{C}$ until assay.

Assays for tPA, tPA activity, PAI-1, hydroxyproline and protein

tPA (IMUBIND ${ }^{\circledR}$ Plasma tPA ELISA, American Diagnostica Inc., Stamford, CT, USA), tPA activity (Chromolize $^{\circledR}$ tPA Assay Kit, Biopool, Trinity Biotech plc., Bray, Co., Wicklow, Ireland), PAI-1 (IMUBINND ${ }^{\circledR}$ Plasma PAI-1 ELISA, American Diagnostica Inc.) and tPA/PAI-1 complex (Haemochrom Diagnostica ELISA tPA-PAI-1 complex GmbH Kleverkämpchen, Essen, Germany) were determined by enzyme-linked immunosorbent assay (ELISA) in accordance with the manufacturer's instructions. The absorbances of the wells were measured in a microplate reader. The standard curves were drawn for each parameter separately through absorbance values of standard solutions. The concentration of the tPA, tPA activity, PAI- 1 and tPA/PAI- 1 complex were calculated in view of this standard curves.

The hydroxyproline values were calculated in dry tissue samples with the partially modified Woessner method (Woessner 1961).

The protein contents of the supernatants were assayed with Lowry method. tPA, tPA activity, PAI-1 and
tPA/PAI-1 complex concentrations were normalized with the protein contents in the supernatants. The results of tPA, PAI-1 and tPA/PAI-1 complex parameters were described as $\mathrm{ng} / \mathrm{mg}$ protein and tPA activity as IU/mg protein.

\section{Statistical analysis}

Results are given as mean \pm S.D. Mann Whitney's $\mathrm{U}$-test was used to compare the adhesion grades in groups. Mann Whitney's U-test was also used to determine the significance of differences in the hydroxyproline content and normalized values of tPA, tPA activity, PAI-1 and tPA/PAI- 1 complex assays. $P<0.05$ was considered significant. The statistical analysis was performed by using the Statistical Package for Social Sciences (SPSS for Windows Release 10.0, Chicago, IL, USA).

\section{Results}

\section{Adhesion formation}

The adhesion grades were significantly lower in IP $(0.80 \pm 0.77)$ and IV pentoxifylline groups $(1.07 \pm 0.80)$ than the control group $(2.0 \pm 0.76)$ ( $p=0.001$ and $p=0.006$ respectively, Fig. 1). Adhesion scores tended to be lower in IP pentoxifylline than the IV pentoxifylline group, but the difference was not significant ( $p=0.353)$ (Fig. 1).

$t P A$

In both IP $(21.72 \pm 11.09 \mathrm{ng} / \mathrm{mg}$ protein $)$ and IV $(21.60 \pm 12.18 \mathrm{ng} / \mathrm{mg}$ protein $)$ pentoxifylline groups, tPA levels were twofold higher in peritoneal samples compared with the control group $(9.61 \pm 4.22 \mathrm{ng} / \mathrm{mg}$ protein $)(p<0.001$ and $p=$ 0.001 , respectively). No significant differences were encountered in tPA levels regarding the route of pentoxifylline administration $(p=0.723)$ (Table 2, Fig. 2). 


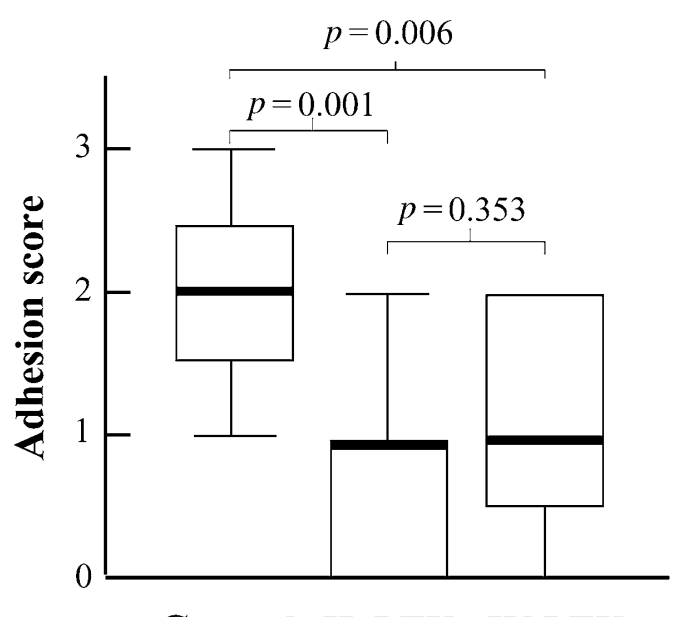

Control IP PTX IV PTX

Fig. 1. Adhesion scores. Values are median (horizontal bars), with interquartile range (boxes) and 10 - 90th centile (error bars). Mann Whitney's U-test was used.

\section{tPA activity}

The levels of tPA activity were found higher in IP $(53.85 \pm 10.33 \mathrm{IU} / \mathrm{mg}$ protein $)$ and IV (41.58 $\pm 10.85 \mathrm{IU} / \mathrm{mg}$ protein) pentoxifylline groups than the control group $(30.58 \pm 7.14 \mathrm{IU} / \mathrm{mg}$ protein $)$ $(p<0.001, p=0.003$, respectively). On the other hand, mean tPA activity was higher in animals receiving IP pentoxifylline compared to animals

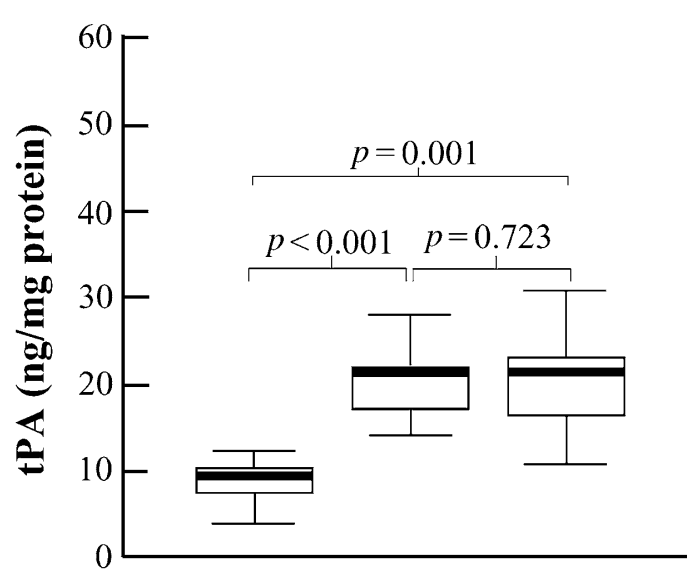

\section{Control IP PTX IV PTX}

Fig. 2. tPA levels in peritoneal samples. Values are median (horizontal bars), with interquartile range (boxes) and 10 - 90th centile (error bars). Mann Whitney's U-test was used.

receiving IV pentoxifylline $(p=0.005)$ (Table 2 , Fig. 3).

\section{PAI-1}

While PAI-1 levels in IP pentoxifylline group $(5.74 \pm 9.11 \mathrm{ng} / \mathrm{mg}$ protein) were lower than the control group $(17.8 \pm 19.35 \mathrm{ng} / \mathrm{mg}$ protein $)$ $(p=0.048)$, there was no significant difference

TABLE 2. Parameters of peritoneal fibrinolysis and hydroxyproline levels in the biopsy specimens.

\begin{tabular}{|c|c|c|c|c|c|}
\hline \multirow{2}{*}{$\begin{array}{c}\text { Parameters } \\
\text { tPA } \\
\text { (ng/mg protein) }\end{array}$} & \multirow{2}{*}{$\begin{array}{c}\text { Control } \\
9.61 \pm 4.22^{\mathrm{a}}\end{array}$} & \multicolumn{2}{|c|}{ IP PTX and $p$ value } & \multicolumn{2}{|c|}{ IV PTX and $p$ value } \\
\hline & & $21.72 \pm 11.09$ & $<0.001^{\mathrm{b}}$ & $21.60 \pm 12.18$ & $0.001^{\mathrm{b}}$ \\
\hline $\begin{array}{l}\text { tPA activity } \\
\text { (IU/mg protein) }\end{array}$ & $30.58 \pm 7.14$ & $53.85 \pm 10.33$ & $<0.001$ & $41.58 \pm 10.85$ & 0.003 \\
\hline $\begin{array}{c}\text { PAI-1 } \\
\text { (ng/mg protein) }\end{array}$ & $17.8 \pm 19.35$ & $5.74 \pm 9.11$ & 0.048 & $11.42 \pm 8.34$ & 0.739 \\
\hline $\begin{array}{l}\text { tPA/PAI-1 complex } \\
\text { (ng/mg protein) }\end{array}$ & $6.50 \pm 2.28$ & $6.32 \pm 1.17$ & 0.819 & $5.62 \pm 0.59$ & 0.109 \\
\hline $\begin{array}{l}\text { Hydroxyproline } \\
(\mu \mathrm{g} / \mathrm{mg} \text { tissue })\end{array}$ & $52.70 \pm 14.04$ & $53.57 \pm 4.27$ & 0.269 & $50.57 \pm 3.33$ & 0.775 \\
\hline
\end{tabular}

Mann Whitney's U-test was used to determine the significance of differences in the normalized values of tPA, tPA activity, PAI-1 and tPA/PAI-1 complex assays and HP contents.

${ }^{a}$ Results are mean \pm S.D.

${ }^{\mathrm{b}} P$ values are concerning about the comparisons between control and experimental groups. 


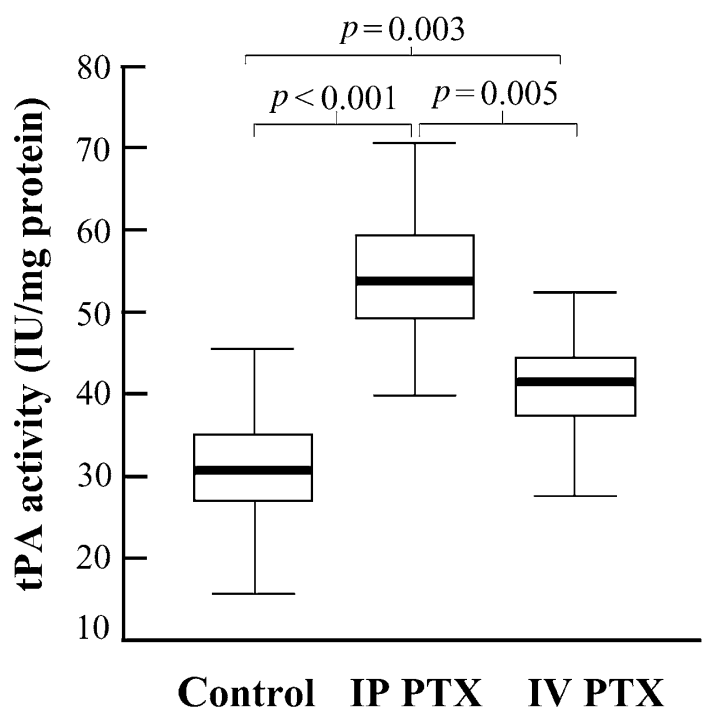

Fig. 3. tPA activity levels in peritoneal samples. Values are median (horizontal bars), with interquartile range (boxes) and 10 - 90th centile (error bars). Mann Whitney's U-test was used.

between IV pentoxifylline $(11.42 \pm 8.34 \mathrm{ng} / \mathrm{mg}$ protein) and control group ( $p=0.739)$. PAI-1 levels differed significantly among the IP and IV pentoxifylline groups ( $p=0.015)$ (Table 2, Fig. 4).

\section{tPA/PAI-1 complex}

There were no differences in the levels of tPA/PAI-1 complex between the control group $(6.50 \pm 2.28 \mathrm{ng} / \mathrm{mg}$ protein $)$ and both IP $(6.32 \pm$ $1.17 \mathrm{ng} / \mathrm{mg}$ protein) and IV $(5.62 \pm 0.59 \mathrm{ng} / \mathrm{mg}$ protein) pentoxifylline group ( $p=0.819$ and $p=$ 0.109). However, tPA/PAI-1 complex levels were slightly lower in IP pentoxifylline group than IV pentoxifylline group ( $p=0.043$ ) (Table 2, Fig. 5).

\section{Hydroxyproline}

Peritoneal hydroxyproline measurements did not differ significantly among the groups ( $p=$ $0.269, p=0.755, p=0.128$, respectively) (Table 2).

\section{Discussion}

Present investigation demonstrated that IP and IV administrations of pentoxifylline reduced peritoneal adhesion formation. Higher tPA and tPA activity levels and lower PAI-1 levels in

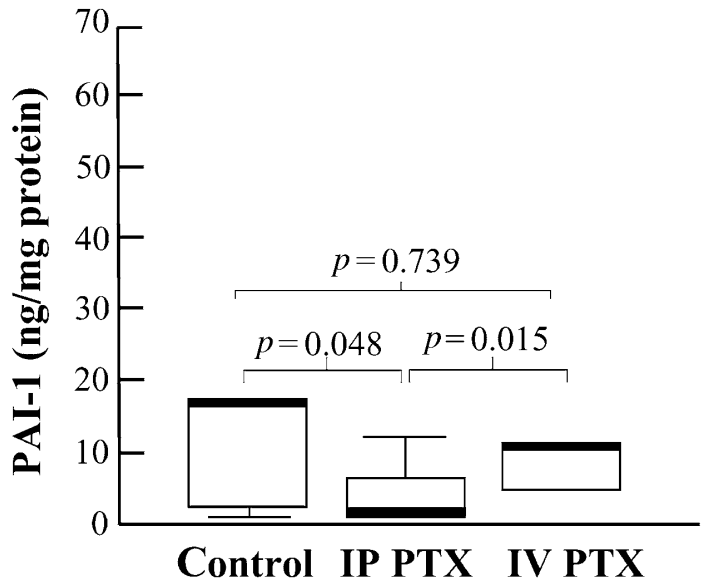

Fig. 4. PAI-1 levels in peritoneal samples. Values are median (horizontal bars), with interquartile range (boxes) and 10 - 90th centile (error bars). Mann Whitney's U-test was used.

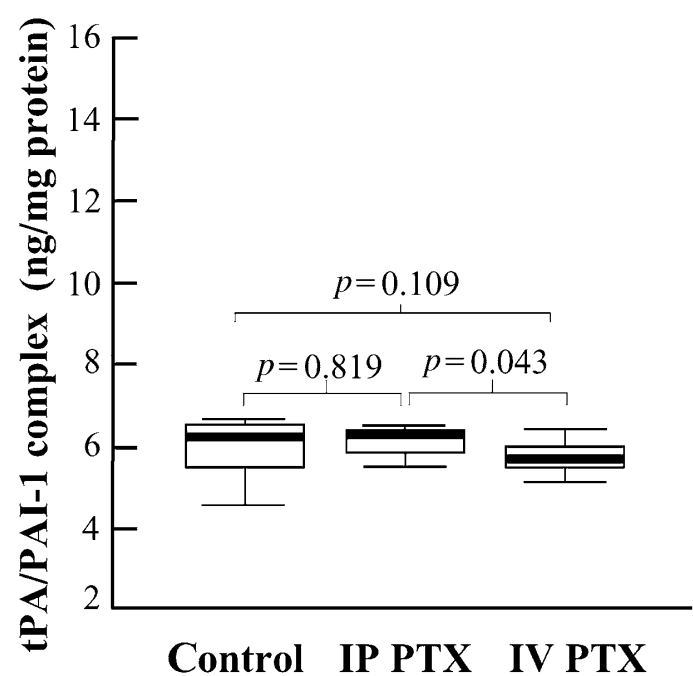

Fig. 5. tPA/PAI-1 complex levels in peritoneal samples. Values are median (horizontal bars), with interquartile range (boxes) and 10 - 90th centile (error bars). Mann Whitney's U-test was used.

experimental groups indicate that both application manners improved fibrinolysis within the peritoneum. The improvement was more prominent in IP pentoxifylline group (Figs. 1 - 5). Although adhesion scores were slightly lower in the IP pentoxifylline group than the IV pentoxifylline group, this was not statistically different. Pentoxifylline did not change hydroxyproline 
levels of peritoneum in our study.

Several animal experiments proved satisfactory results in pentoxifylline administration to the peritoneal adhesions prevention (Chalkiadakis et al. 1985; Steinleitner et al. 1990; Lai et al. 1994; Kaleli et al. 1998). In a peritonitis model, which was induced in rats by creating a closed ileal loop, 30 - day intramuscular pentoxifylline administration increased the survival of animals and reduced adhesion and abscess formation (Chalkiadakis et al. 1985). Steinleitner et al. (1990) demonstrated a marked inhibition of adhesion reformation after lysis of pelvic adhesions in rabbit uterine horn model with the three-day subcutaneous pentoxifylline treatment. In an another experimental rat model of intestinal resection and reanastomosis, IP pentoxifylline irrigation and irrigation plus 14 day intramuscular pentoxifylline injection resulted significantly and equally reduced adhesion at the anastomotic site (Lai et al. 1994). Kaleli et al. (1998) reported that the IP application of L-arginine and pentoxifylline reduced adhesion formation equally in rat uterine horn model.

Data from these studies showed that both IP and systemic pentoxifylline administration reduced the development of adhesions. However, the effects of pentoxifylline on peritoneal fibrinolysis were not investigated so far. Our model confirmed and extended these findings. Ivarsson et al. (1998) suggested that there was covariance in the levels of PAI-1 and tPA/PAI-1 complex, because PAI-1 inhibits fibrin degradation by forming inactive complexes with plasminogen activators. However, there was no parallelism or connection between the levels of tPA/PAI-1 complexes and other peritoneal fibrinolytic parameters among the three groups in our study.

Numerous agents have been used to reduce postoperative adhesions. Seprafilm is such a commercially available material. The safety and efficacy of this membrane in preventing postoperative adhesion has been demonstrated in clinical and experimental studies (Becker and Dayton 1996; Kelekci et al. 2004). It was pointed out that Seprafilm had no major effect on peritoneal fibrinolysis but it increased peritoneal hydroxyproline (Altuntas et al. 2002; Tarhan et al. 2005).
A drawback of our experimental design could be the lack of application of sterile water to the control animals. We were not able to locate any data in the literature about the effectivity of sterile water in peritoneal adhesions. However, it seems unlikely that the reduction in peritoneal adhesions is solely attributable to sterile water rather than pentoxifylline.

We conclude that adhesion preventive effects of pentoxifylline administration may result from its positive effects on peritoneal fibrinolysis.

\section{Acknowledgments}

The authors wish to thank Mustafa Ozturk, M.D., working at the Department of Public Health, Suleyman Demirel University Medical School, for his assistance with the statistical analysis.

We also want to thank to Omer Sekerci, Ph.D., working at the Department of English Language and Literature at the faculty of Science and Letters, Suleyman Demirel University, Mekin Sezik, M.D., working at the Department of Gynecology and Obstetrics at the faculty of Medicine, Suleyman Demirel University, for his help in the correction of the language of the article.

\section{References}

Alkharfy, K.M., Kellum, J.A. \& Matzke, G.R. (2000) Unintended immunomodulation: part II. Effects of pharmacological agents on cytokine activity. Shock, 13, 346-360.

Altuntas, I., Tarhan, O., Delibas, N., Cetin, R. \& Sutcu, R. (2002) Seprafilm reduces adhesions to polypropylene mesh and increases peritoneal hydroxyproline. Am. Surg., 68, 759-761.

Becker, J.M. \& Dayton, M.T. (1996) Prevention of postoperative abdominal adhesions by a sodium hyaluronatebioresorbable membrane: A prospective, randomized, double-blind multicenter study. J. Am. Coll. Surg., 183, 297-305.

Chalkiadakis, G.E., Kostakis, A., Karayannacos, P.E., Chalkiadakis, M.E., Sgouromali, S. \& Giamarellou, H. (1985) Pentoxifylline in the treatment of experimental peritonitis in rats. Arch. Surg., 120, 1141-1144.

Evans, D.M., McAree, K., Guyton, D.P., Hawkins, N. \& Stakleff, K. (1993) Dose dependency and wound healing aspects of the use of tissue plasminogen activator in the prevention of intra-abdominal adhesions. Am. J. Surg., 165, 229-232.

Holtz, G. (1984) Prevention and management of peritoneal adhesions. Fertil. Steril., 41, 497-507.

Ivarsson, M.L., Bergstrom, M., Eriksson, E., Risberg, B. \& Holmdahl, L. (1998) Tissue markers as predictors of postoperative adhesions. Br. J. Surg., 85, 1549-1554.

Jarret, P.E., Moreland, M. \& Browse, N.L. (1977) The effect of oxpentifylline ('Trental') on fibrinolytic activity and plasma fibrinogen levels. Curr. Med. Res. Opin., 4, 492-495.

Kaleli, B., Ozden, A., Aybek, Z. \& Bostanci, B. (1998) The 
effect of L-arginine and pentoxifylline on postoperative adhesion formation. Acta Obstet. Gynecol. Scand., 77, 377-380.

Kelekci, S., Yilmaz, B., Oguz, S., Zergeroglu, S., Inan, I. \& Tokucoglu, S. (2004) The efficacy of a hyaluronate/ carboxymethylcellulose membrane in prevention of postoperative adhesion in a rat uterine horn model. Tohoku J. Exp. Med., 204, 189-194.

Lai, H.S., Chu, S.Y., Chen, Y., Wu, C.H. \& Lin, L.T. (1994) Effect of pentoxifylline on intraperitoneal adhesions after intestinal resection in rats. J. Formos. Med. Assoc., 93, 911-915.

Menzies, D. (2004) Adhesions: the cellular science. Hosp. Med., 65, 337-339.

Menzies, D. \& Ellis, H. (1990) Intestinal obstruction from adhesions-how big is the problem? Ann. R. Coll. Surg. Engl., 72, 60-63.
Raftery, A.T. (1981) Effect of peritoneal trauma on peritoneal fibrinolytic activity and peritoneal adhesion formation. An experimental study in the rat. Eur. Surg. Res., 13, 397-401.

Schroer, R.H. (1985) Antithrombotic potential of pentoxifylline. A hemorheologically active drug. Angiology, 36, 387-398.

Steinleitner, A., Lambert, H., Kazensky, C., Danks, P. \& Roy, S. (1990) Pentoxifylline, a methylxanthine derivative, prevents postsurgical adhesion reformation in rabbits. Obstet. Gynecol., 75, 926-928.

Tarhan, O.R., Eroglu, A., Cetin, R., Ynce, A., Bulbul, M. \& Altuntas, Y.R. (2005) Effects of seprafilm on peritoneal fibrinolytic system. A. NZ J. Surg., 75, 690-692.

Woessner, J.B. (1961) The determination of hydroxiproline in tissue and protein samples containing small proportions of this imino acid. Arc. Biochem. Biophy., 93, 440-447. 